\title{
Convergence of CR Iterative Scheme with Errors using Quasi-Contractive Operators
}

\author{
Meenakshi Gugnani \\ Department of Mathematics \\ Sh. L. N. Hindu College \\ ROHTAK, INDIA
}

\author{
Renu Chugh \\ Department of Mathematics \\ Maharshi Dayanand University \\ ROHTAK, INDIA
}

\begin{abstract}
The aim of this article is to introduce a new iterative scheme namely CR iterative scheme with errors and prove a general convergence theorem to approximate the unique common fixed point of three operators satisfying a certain contractive condition in an arbitrary Banach space using this newly introduced iterative scheme. An example showing the validity of our results is provided. Comparative analysis of new iterative scheme with already existing iterative schemes is also shown using programming in $\mathrm{C}++$.
\end{abstract}

\section{General Terms}

Computational Mathematics

\section{Keywords}

CR Iterative Scheme; Quasi-contractive Operators.

\section{INTRODUCTION AND PRELIMINARIES}

In the recent years, fixed and common points of contractive type self operators have been approximated by various authors using different iterative schemes [2-5, 9, 10, 12-19]. Let $(X, d)$ be a complete metric space and $T: X \rightarrow X$ a selfmap of $X$. Suppose that $F_{T}=\{p \in X, T p=p\}$ is the set of fixed points of $T$. In a complete metric space, the Picard iterative scheme $\left\{x_{n}\right\}_{n=0}^{\infty}$ defined by

(1.1)

$$
x_{n+1}=T x_{n}, n=0,1, \ldots
$$

has been employed to approximate the fixed points of mappings satisfying the inequality

$d(T \mathrm{x}, T y) \leq \alpha d(x, y)$, for all $x, y \in X$ and $\alpha \in[0,1)$.

Condition (1.2) is called the Banach's contraction condition.

After consideration of errors terms in iterative schemes, in 1995, Liu[10] introduced iterative scheme with errors as follows :

$$
\begin{aligned}
& x_{n+1}=\left(1-\alpha_{n}\right) x_{n}+\alpha_{n} T y_{n}+u_{n} \\
& y_{n}=\left(1-\beta_{n}\right) x_{n}+\beta_{n} T x_{n}+v_{n}, \quad n \geq 0,
\end{aligned}
$$

where $\left\{\alpha_{n}\right\},\left\{\beta_{n}\right\}$ are sequences in $[0,1]$ and $u_{n}, v_{n}$ are summable sequences in $K, K$ being a closed, convex subset of a Banach space $X$.
But in succeeding years it was observed that the iterative process with errors introduced by Liu [10] was not satisfactory. The errors occur in a random way. The conditions imposed on the errors terms in (1.3) which say that they tend to zero as $n$ tends to infinity are, therefore, unreasonable. In [19] Xu introduced Ishikawa iterative with errors with a more satisfactory error terms:

$$
\begin{aligned}
x_{n+1} & =\alpha_{n} x_{n}+\alpha_{n}^{1} T y_{n}+a_{n} u_{n} \\
y_{n} & =\beta_{n} x_{n}+\beta_{n}^{1} T x_{n}+b_{n} v_{n}, \quad n \geq 0,
\end{aligned}
$$

where $\left\{\alpha_{n}\right\},\left\{\beta_{n}\right\},\left\{a_{n}\right\},\left\{b_{n}\right\},\left\{\alpha_{n}^{1}\right\},\left\{\beta_{n}^{1}\right\}$ are sequences in $[0,1]$ with $\alpha_{n}+\alpha_{n}^{1}+a_{n}=\beta_{n}+\beta_{n}^{1}+b_{n}=1$ and $u_{n}, v_{n}$, are summable sequences in $K$.

If $b_{n}=a_{n}=\alpha_{n}^{1}=\beta_{n}^{1}=0$, then (1.4) reduces to Mann iterative scheme with errors:

$x_{n+1}=\alpha_{n} x_{n}+\alpha_{n}^{1} T x_{n}+a_{n} u_{n}, n \geq 0$.

(1.5)

In 2002, Agarwal et al. [5] studied the following iterative scheme:

$$
\begin{aligned}
& x_{n+1}=\alpha_{n} T x_{n}+\alpha_{n}^{1} T y_{n} \\
& y_{n}=\beta_{n} x_{n}+\beta_{n}^{1} T x_{n}, n \geq 0,
\end{aligned}
$$

where $\left\{\alpha_{n}\right\},\left\{\beta_{n}\right\},\left\{\alpha_{n}^{1}\right\},\left\{\beta_{n}^{1}\right\}$ are sequences in [0,1] with $\alpha_{n}+\alpha_{n}^{1}=\beta_{n}+\beta_{n}^{1}=1$.

In 2009, Khan [8] studied the convergence of following iterative scheme with errors to approximate the common fixed point of two $\mathrm{Z}$ operators:

$$
\begin{gathered}
x_{n+1}=\alpha_{n} x_{n}+\alpha_{n}^{1} T_{1} y_{n}+a_{n} u_{n} \\
y_{n}=\beta_{n} x_{n}+\beta_{n}^{1} T_{2} x_{n}+b_{n} v_{n}
\end{gathered}
$$

where $\left\{\alpha_{n}\right\},\left\{\beta_{n}\right\},\left\{a_{n}\right\},\left\{b_{n}\right\},\left\{\alpha_{n}^{1}\right\},\left\{\beta_{n}^{1}\right\}$ are sequences in $[0,1]$ with $\alpha_{n}+\alpha_{n}^{1}+a_{n}=\beta_{n}+\beta_{n}^{1}+b_{n}=1$ and $u_{n}, \quad v_{n}, \quad$ are summable sequences in $K$.

In 1972, Zamfirescu [20] obtained the following theorem: 
Theorem 1.1. Let $(X, d)$ be a complete metric space and $T$ : $\mathrm{X} \rightarrow \mathrm{X}$ a mapping for which there exists the real numbers $a$, $b$ and $c$ satisfying $a \in(0,1), b, c \in\left(0, \frac{1}{2}\right)$ such that for each pair $x, y \in \mathrm{X}$ at least one of the following conditions hold

(i) $d(T x, T y) \leq a d(x, y)$

(ii) $d(T x, T y) \leq b[d(x, T x)+d(y, T y)]$

(iii) $d(T x, T y) \leq c[d(x, T y)+d(y, T x)]$.

Then $T$ has a unique fixed point $p$ and the Picard iterative scheme $\left\{x_{n}\right\}$ defined by (1.1) converges to $p$ for any arbitrary but fixed $x_{0} \in X$.

The operators satisfying the condition (1.8) are called Zamfirescu operators.

Berinde[3] introduced a new class of operators on an arbitrary Banach space satisfying

$$
d(T x, T y) \leq 2 \delta d(x, T x)+\delta d(x, y),
$$

$\forall \mathrm{x}, \mathrm{y} \in \mathrm{X}$ and $\delta \in[0,1)$. He proved that this class is wider than the class of Zamfirescu operators and used the Ishikawa iterative process to approximate fixed points of this class of operators in an arbitrary Banach space given in the form of following theorem.

Theorem 1.2[3] Let $K$ be a nonempty closed convex subset of an arbitrary Banach space $X$ and $T: K \rightarrow K$ a mapping satisfying (1.9). Let $\left\{s_{n}\right\}_{n=0}^{\infty}$ defined through the Ishikawa iterative (1.4) and $x_{0} \in K$, where $\left\{\alpha_{n}\right\},\left\{\beta_{n}\right\}$ are sequences of positive numbers in $[0,1]$ with $\left\{\alpha_{n}\right\}$ satisfying $\sum_{n=0}^{\infty} \alpha_{n}=\infty$. Then $\left\{x_{n}\right\}_{n=0}^{\infty}$ converges strongly to the fixed point of $T$.

In 2012, for $\alpha_{\mathrm{n}}, \beta_{\mathrm{n}}, \gamma_{\mathrm{n}} \in[0,1]$, Chugh and Kumar[5] introduced the $\mathrm{CR}$ iterative scheme as below:

(CR)

$$
\begin{gathered}
x_{n+1}=\left(1-\alpha_{n}\right) y_{n}+\alpha_{n} T y_{n} \\
y_{n}=\left(1-\beta_{n}\right) T x_{n}+\beta_{n} T z_{n} \\
z_{n}=\left(1-\gamma_{n}\right) x_{n}+\gamma_{n} T x_{n}
\end{gathered}
$$

Inspired by the above mentioned works, for contractive type operators $T_{1}, T_{2}$ and $T_{3}$, we define the $C R$ iterative scheme with errors as below:

$$
\begin{gathered}
x_{n+1}=a_{n} y_{n}+b_{n} T_{1} y_{n}+c_{n} u_{n} \\
y_{n}=a_{n}^{\prime} T_{3} x_{n}+b_{n}^{\prime} T_{2} z_{n}+c_{n}^{\prime} v_{n} \\
z_{n}=a_{n}^{\prime \prime} x_{n}+b_{n}^{\prime \prime} T_{3} x_{n}+c_{n}^{\prime \prime} w_{n}, n \geq 0,
\end{gathered}
$$

where $\left\{a_{n}\right\},\left\{b_{n}\right\},\left\{c_{n}\right\},\left\{a_{n}^{\prime}\right\},\left\{b_{n}^{\prime}\right\},\left\{c_{n}^{\prime}\right\},\left\{a_{n}^{\prime \prime}\right\},\left\{b_{n}^{\prime \prime}\right\},\left\{c_{n}^{\prime \prime}\right\}$ are sequences in $[0,1]$ with $a_{n}+b_{n}+c_{n}=a_{n}^{\prime}+b_{n}^{\prime}+c_{n}^{\prime}=a_{n}^{\prime \prime}+$ $b_{n}^{\prime \prime}+c_{n}^{\prime \prime}=1$ and $u_{n}, v_{n}, w_{n}$, are summable sequences in $K$.

\section{Remarks:}

1. If $b_{n}=c_{n}=b_{n}^{\prime}=c_{n}^{\prime}=0$ and $\mathrm{T}_{3}=\mathrm{T}$, then (1.10) reduces to Mann iterative scheme with errors:

$$
x_{n+1}=a_{n}^{\prime \prime} x_{n}+b_{n}^{\prime \prime} T x_{n}+c_{n}^{\prime \prime} w_{n}, \quad n \geq 0 \text {. }
$$

2. If $b_{n}=c_{n}=0$ and $\mathrm{T}_{3}=\mathrm{T}_{2}=\mathrm{T}$, then (1.10) reduces to

Agarwal et al. iterative scheme with errors:

$$
\begin{aligned}
& x_{n+1}=a_{n}^{\prime} T x_{n}+b_{n}^{\prime} T z_{n}+c_{n}^{\prime} v_{n} \\
& z_{n}=a_{n}^{\prime \prime} x_{n}+b_{n}^{\prime \prime} T x_{n}+c_{n}^{\prime \prime} w_{n}, \quad n \geq 0 .
\end{aligned}
$$

To prove our main results, we use the following Lemma:

Lemma 1.3.[2] If $\delta$ is a real number such that $0 \leq \delta<1$ and $\left\{\in_{n}\right\}_{n=0}^{\infty}$ is a sequence of positive numbers such that $\lim _{n \rightarrow \infty}$ $\epsilon_{n}=0$, then for any sequence of positive numbers $\left\{u_{n}\right\}_{n=0}^{\infty}$ satisfying

$$
u_{n+1} \leq \delta u_{n}+\in_{n}, n=0,1,2, \ldots
$$

we have $\lim _{n \rightarrow \infty} u_{n}=0$.

The purpose of this paper to study the strong convergence of CR iterative scheme with errors (1.10) to the common fixed point of three quasi-contractive operators satisfying the following contractive condition: there exists $a \in[0,1)$ and a monotone increasing function $\varphi: \mathrm{R}^{+} \rightarrow \mathrm{R}^{+}$with $\varphi(0)=0$, such that

$$
\|T x-T y\| \leq \varphi(\|x-T x\|)+a\|x-y\| \forall x, y \in X .
$$

\section{MAIN RESULTS}

Theorem 2.1. Let $K$ be a nonempty closed convex subset of an arbitrary Banach space $X$ and $T_{\mathrm{i}}: K \rightarrow K(\mathrm{i}=1,2,3)$ be three quasi-contractive operators satisfying (1.13). Let $\left\{x_{n}\right\}_{n=0}^{\infty}$ be defined through the $\mathrm{CR}$ iterative scheme with errors (1.10) and $x_{0} \in K$, where $\left\{a_{n}\right\},\left\{b_{n}\right\},\left\{c_{n}\right\},\left\{a_{n}^{\prime}\right\},\left\{b_{n}^{\prime}\right.$ \}$\left\{c_{n}^{\prime}\right\},\left\{a_{n}^{\prime \prime}\right\},\left\{b_{n}^{\prime \prime}\right\},\left\{c_{n}^{\prime \prime}\right\}$ are sequences in $[0,1]$ are sequences in [0,1] satisfying $\lim c_{n}^{\prime}=0=\lim c_{n}{ }_{n}=0$. If $\mathrm{F}\left(\mathrm{T}_{1}\right) \cap \mathrm{F}\left(\mathrm{T}_{2}\right)$ $\cap \mathrm{F}\left(\mathrm{T}_{3}\right) \neq \phi$, then $\left\{x_{n}\right\}_{n=0}^{\infty}$ converges strongly to the unique common fixed point of $T_{1}, \mathrm{~T}_{2}$ and $\mathrm{T}_{3}$.

Proof : If $p \in \mathrm{F}\left(\mathrm{T}_{1}\right) \cap \mathrm{F}\left(\mathrm{T}_{2}\right) \cap \mathrm{F}\left(\mathrm{T}_{3}\right) \neq \phi$, then it follows from Theorem 1.1 that $p$ is a unique common fixed point of $T_{1}, \mathrm{~T}_{2}$ and $\mathrm{T}_{3}$. 
Since $\mathrm{K}$ is bounded, we can choose a number $\mathrm{M}$ such that $\mathrm{M}=$ $\operatorname{Max}\left\{\sup _{n \geq 0}\left\|u_{n}-y_{n}\right\|, \sup _{n \geq 0}\left\|v_{n}-T_{3} x_{n}\right\|, \sup _{n \geq 0}\left\|w_{n}-x_{n}\right\|\right\}$, therefore from (1.10), we have

$\left\|x_{n+1}-p\right\|=\left\|a_{n} y_{n}+b_{n} T_{1} y_{n}+c_{n} u_{n}-\left(a_{n}+b_{n}+c_{n}\right) p\right\|$

$$
\begin{aligned}
& =\left\|\left(1-b_{n}\right)\left(y_{n}-p\right)+b_{n}\left(T_{1} y_{n}-p\right)+c_{n}\left(u_{n}-y_{n}\right)\right\| \\
& \leq\left(1-b_{n}\right)\left\|y_{n}-p\right\|+b_{n}\left\|T_{1} y_{n}-p\right\|+c_{n}\left\|u_{n}-y_{n}\right\| \\
& \leq\left(1-b_{n}\right)\left\|y_{n}-p\right\|+b_{n} \delta\left\|y_{n}-p\right\|+c_{n} \mathrm{M} \\
& =\left(1-b_{n}(1-\delta)\right)\left\|y_{n}-p\right\|+c_{n} \mathrm{M} .
\end{aligned}
$$

$$
\text { Now, we have the following }
$$

estimates :

$\left\|y_{n}-p\right\|=\left\|a_{n}^{\prime} T_{3} x_{n}+b_{n}^{\prime} T_{2} z_{n}+c_{n}^{\prime} v_{n}-\left(a_{n}^{\prime}+b_{n}^{\prime}+c_{n}^{\prime}\right) p\right\|$

$$
\begin{gathered}
=\left\|\left(1-b_{n}^{\prime}\right)\left(T_{3} x_{n}-p\right)+b_{n}^{\prime}\left(T_{2} z_{n}-p\right)+c_{n}^{\prime}\left(v_{n}-T_{3} x_{n}\right)\right\| \\
\leq\left(1-b_{n}^{\prime}\right) \delta\left\|x_{n}-p\right\|+b_{n}^{\prime} \delta\left\|z_{n}-p\right\|+c_{n}^{\prime} M
\end{gathered}
$$

and

$\left\|z_{n}-p\right\|=\left\|a_{n}^{\prime \prime} x_{n}+b_{n}^{\prime \prime} T_{3} x_{n}+c_{n}^{\prime \prime} w_{n}-\left(a_{n}^{\prime \prime}+b_{n}^{\prime \prime}+c_{n}^{\prime \prime}\right) p\right\|$

$=\left\|\left(1-b_{n}^{\prime \prime}\right)\left(x_{n}-p\right)+b_{n}^{\prime \prime}\left(T_{3} x_{n}-p\right)+c_{n}^{\prime \prime}\left(w_{n}-x_{n}\right)\right\|$

$\leq\left(1-b_{n}^{\prime \prime}\right)\left\|x_{n}-p\right\|+b_{n}^{\prime \prime}\left\|T_{3} x_{n}-p\right\|+c_{n}{ }_{n}\left\|w_{n}-x_{n}\right\|$

$$
\begin{aligned}
& \leq\left(1-b_{n}^{\prime \prime}\right)\left\|x_{n}-p\right\|+b_{n}^{\prime \prime} \delta\left\|x_{n}-p\right\|+c_{n}{ }_{n} \mathrm{M} \\
& =\left(1-b_{n}^{\prime \prime}(1-\delta)\right)\left\|x_{n}-p\right\|+c_{n}^{\prime \prime} \mathrm{M} .
\end{aligned}
$$

Using estimates (2.2) and (2.3), (2.1) yields

$$
\begin{gathered}
\left\|x_{n+1}-p\right\| \leq\left(1-b_{n}(1-\delta)\right)\left[\left(1-b_{n}^{\prime}\right) \delta\left\|x_{n}-p\right\|\right. \\
\left.+b_{n}^{\prime} \delta\left(1-b_{n}^{\prime \prime}(1-\delta)\right)\left\|x_{n}-p\right\|\right] \\
+\left(1-b_{n}(1-\delta)\right) b_{n}^{\prime} \delta c_{n}^{\prime \prime} \mathrm{M} \\
\quad+\left(1-b_{n}(1-\delta)\right) c_{n}^{\prime} M+c_{n} M \\
\leq\left(1-b_{n}(1-\delta)\right)\left\|x_{n}-p\right\|+M\left(c_{n}+c_{n}^{\prime}+c_{n}^{\prime \prime}\right)
\end{gathered}
$$

Since $\lim _{\mathrm{n} \rightarrow \infty} c_{n}=\lim _{\mathrm{n} \rightarrow \infty} c_{n}^{\prime}=\lim _{\mathrm{n} \rightarrow \infty} c_{n}^{\prime \prime}=0$, hence using Lemma 1, (2.4) yields $\lim _{n \rightarrow \infty}\left\|x_{n}-p\right\|=0$. Therefore $\left\{x_{n}\right\}_{n=0}^{\infty}$ converges strongly to $p$.

Corollary 2.2. Let $K$ be a nonempty closed convex subset of an arbitrary Banach space $X$ and $T_{\mathrm{i}}: K \rightarrow K(\mathrm{i}=1,2)$ be two quasi-contractive operators satisfying (1.13). Let $\left\{x_{n}\right\}_{n=0}^{\infty}$ be defined through the iterative scheme with errors (1.12) and $x_{0} \in K$, where $\left\{a_{n}^{\prime}\right\},\left\{b_{n}^{\prime}\right\}\left\{c_{n}^{\prime}\right\},\left\{a_{n}^{\prime \prime}\right\},\left\{b_{n}^{\prime \prime}\right\},\left\{c_{n}^{\prime \prime}\right.$ \}are sequences in $[0,1]$ satisfying $\lim c_{n}^{\prime}=0=\lim c_{n}{ }_{n}=0$. If $\mathrm{F}\left(\mathrm{T}_{1}\right) \cap \mathrm{F}\left(\mathrm{T}_{2}\right) \neq \phi$, then $\left\{x_{n}\right\}_{n=0}^{\infty}$ converges strongly to the unique common fixed point of $T_{1}$ and $\mathrm{T}_{2}$.

Corollary 2.3. Let $K$ be a nonempty closed convex subset of an arbitrary Banach space $X$ and $T: K \rightarrow K$ be a quasi-contractive operator satisfying (1.13). Let $\left\{x_{n}\right\}_{n=0}^{\infty}$ be defined through the Mann iterative scheme with errors (1.11) and $x_{0} \in K$, where $\left\{a_{n}^{\prime \prime}\right\},\left\{b_{n}^{\prime \prime}\right\},\left\{c_{n}^{\prime \prime}\right\}$ are sequences in $[0,1]$ satisfying $\lim c_{n}=0$. If $\mathrm{F}(\mathrm{T}) \neq \phi$, then $\left\{x_{n}\right\}_{n=0}^{\infty}$ converges strongly to the unique fixed point of $T$.

The following example supports the validity of our results.

Example 2.4. Let $X$ be the real line with the usual norm and let $K=[0,1]$. Define $T_{i}(i=1,2,3): K \rightarrow K$ by

$$
T_{1}(x)=\left\{\begin{array}{l}
\frac{1}{6}, x \in(0.5,1] \\
0, x \in[0,0.5]
\end{array}\right\}
$$

$$
T_{2}(x)=\left\{\begin{array}{l}
\frac{1}{7}, x \in(0.5,1] \\
0, x \in[0,0.5]
\end{array}\right\}
$$

$$
T_{3}(x)=\left\{\begin{array}{l}
\frac{1}{8}, x \in(0.5,1] \\
0, x \in[0,0.5]
\end{array}\right\}
$$

Mappings $T_{1}, T_{2}, T_{3}$ and the set $K$ fulfill the requirements of the Theorem 2.1. If we take, $c_{n}=c_{n}^{\prime}=c_{n}^{\prime \prime}=\frac{1}{n+1}$, $b_{n}=b_{n}^{\prime}=b_{n}^{\prime \prime}=\frac{1}{\sqrt{2 n+1}}, u_{n}=v_{n}=w_{n}=\frac{1}{\sqrt{n^{2}+1}}$, then the sequence $\left\{x_{n}\right\}_{n=0}^{\infty}$ defined by (1.10) converges strongly to unique common fixed point 0 of $T_{1}, T_{2}$ and $T_{3}$.

\section{EXPERIMENTS}

In this section, with the help of computer programming in $\mathrm{C}++$, we study the nature of convergence of Mann, Ishikawa , Agarwal et al. and CR iterative schemes with errors to locate a common fixed point of operators $T_{i}(i=1,2,3)$ as taken in Example 2.4. The outcome is listed in the form of 
Tables 1 by taking initial approximation $\mathrm{x}_{0}=1$ for all iterative schemes.

\section{CONCLUSIONS}

1. Newly introduced iterative scheme namely $\mathrm{CR}$ iterative scheme with errors is indepengent of Ishikawa iterative scheme but more general than Mann and Agarwal et al. iterative schemes.

2. CR iterative scheme with errors have high convergence rate as compared to Mann, Ishikawa and Agarwal et al. iterative schemes with errors.

Table 1

\begin{tabular}{|l|c|l|l|l|}
\hline $\begin{array}{l}\text { No of } \\
\text { iterati- } \\
\text { ons } \\
\text { (n) }\end{array}$ & $\begin{array}{l}\text { CR iterative } \\
\text { scheme with } \\
\text { errors }\end{array}$ & $\begin{array}{l}\text { Ishikawa } \\
\text { iterative } \\
\text { scheme } \\
\text { with } \\
\text { errors }\end{array}$ & $\begin{array}{l}\text { Agarwal et.al. } \\
\text { iterative } \\
\text { scheme with } \\
\text { errors }\end{array}$ & $\begin{array}{l}\text { Mann } \\
\text { iterative } \\
\text { scheme } \\
\text { with } \\
\text { errors }\end{array}$ \\
\hline 0 & 0.25 & 0.02381 & 0.861111 & 0.166667 \\
\hline 1 & 0.014008 & 0.01108 & 0.103652 & 0.086479 \\
\hline 2 & 0.001127 & 0.00657 & 0.014396 & 0.05425 \\
\hline 3 & 0.000106 & 0.00433 & 0.002114 & 0.037163 \\
\hline 4 & $1.093763 \mathrm{e}-05$ & 0.00303 & 0.00032 & 0.02684 \\
\hline 5 & $1.197059 \mathrm{e}-06$ & 0.00221 & $4.924172 \mathrm{e}-05$ & 0.020096 \\
\hline 6 & $1.368042 \mathrm{e}-07$ & 0.00167 & $7.680866 \mathrm{e}-06$ & 0.015451 \\
\hline 7 & $1.615802 \mathrm{e}-08$ & 0.00128 & $1.209025 \mathrm{e}-06$ & 0.012127 \\
\hline 8 & $1.958853 \mathrm{e}-09$ & 0.00101 & $1.916265 \mathrm{e}-07$ & 0.009676 \\
\hline 9 & $2.425776 \mathrm{e}-10$ & 0.00080 & $3.053698 \mathrm{e}-08$ & 0.007826 \\
\hline 10 & $3.057766 \mathrm{e}-11$ & 0.00065 & $4.887532 \mathrm{e}-09$ & 0.006403 \\
\hline
\end{tabular}

\section{ACKNOWLEDGMENTS}

The authors would like to thank to the referee for his/her careful reading of manuscript and their valuable comments.

\section{REFERENCES}

[1] Agarwal, R.P., Cho, Y. J., Li, J. and Huanj, N.J., Stability of iterative procedures with errors approximating fixed points for a couple of quasicontractive operators in q-uniformly smooth Banach spaces, J. Math. Anal. Appl., 272(2002), 435-447.

[2] Berinde, V., Iterative Approximation of Fixed Points, Editura Efemeride (2007).

[3] Berinde, V., On the convergence of Ishikawa iterative in the class of quasicontractive operators, Acta Math. Univ. Comenianae, Vol LXXIII, 1(2004), 119126.

[4] Chugh, R. Kumar, V., Convergence of SP iterative scheme with mixed errors for accretive Lipschitzian and strongly accretive Lipschitzian operators in Banach space, Int. J. Of Computer Mathematics, Vol 2013, 17 pages.

[5] Chugh, R., Kumar, V., Strong convergence of a new three step iterative scheme in Banach spaces, American Journal of Computational Mathematics, 2( 2012), 345357.

[6] Goebel, K. and Kirk, W. A., A fixed point theorem for asymptotically nonexpansive mappings, Proceeding of American mathematical society, Vol 35(1972), 171174.

[7] Ishikawa, S., Fixed Point by a New Iterative Method, Proc. Amer. Math. Soc. 44 (1) (1974), 147-150.

[8] Khan, S. H., Common fixed points of two quasicontractive operators in normed spaces by iteration, Int. Journal of Math. Analysis, Vol3,3 (2009), 145- 151.

[9] Liu, L., Fixed Points of local Strictly Pseudo-contractive Mappings Using Mann and Ishikawa iterative with Errors, Indian J. Pure Appl. Math. 26 (7) (1995), 649659.

[10] Liu, L., Ishikawa and Mann Iterative Processes with Errors for Nonlinear Strongly Accretive Mappings in Banach Spaces, J. Math. Anal. Appl. 194 (1995), 114125 .

[11] Mann, W. R., Mean value methods in iteration, Proc. Amer. Math. Soc., 4(1953),

[12] 506-510.

[13] Noor, M.A., New approximation schemes for general variational inequalities, Journal of Mathematical Analysis and Applications, 251(1)(2004), 217-229.

[14] Olaleru, J.O., On the convergence of the Mann iterative in locally convex spaces, Carpathian Journal of Mathematics, 22(1-2)(2006), 115-120.

[15] Rafiq, A., A Convergence Theorem for Mann Fixed Point Iterative Procedure, Applied Mathematics E-Notes 6 (2006), 289-293.

[16] Rashwan, R.A., Rafiq, A. and Hakim, A.: On the convergence of three-step iterative process with errors in the classs of quasi-contractive operators, Proc. Pakistan Acad. Sci. 46(1) (2009), 41-46.

[17] Rhoades, B.E., Some Fixed Point Iterative Procedures, Int. J. Math. Math. Sci., 14 (1) (1991), 1-16.

[18] Rhoades, B.E., Comments On Two Fixed Point Iterative Methods, J. Math. Anal. Appl. 56 (2) (1976), 741-750.

[19] Thianwan, S., Common fixed points of new iterations for two asymptotically nonexpansive nonself mappings in Banach spaces, Journal of Computational and Applied Mathematics, 2009,688 -695.

[20] $\mathrm{Xu}, \mathrm{Y}$., Ishikawa and Mann iterative process with errors for non-linear accretive operator equations, J. Math. Appl. 224(1998), 91-101.

[21] Zamfirescu, T., Fix Point Theorems in Metric Spaces, Arch. Math. 23 (1972), 292- 298.

[22] Zeidler, E., Nonlinear Functional Analysis and its Applications, Fixed-Point Theorems I., SpringerVerlag, New York, Inc. (1986). 